\title{
Política indutora brasileira de formação em saúde: avaliação do desenvolvimento da formação integral para o SUS
}

\section{Brazilian induction policy on health training: evaluating the development of integral training for the SUS}

\author{
Bruna Nadaletti de Araujo', Carla Beatrice Crivellaro Gonçalves², Júlio Cesar Godoy Bertolin ${ }^{3}$ \\ 'Autora para correspondência. Universidade Federal da Fronteira Sul - UFFS, Chapecó, Santa Catarina,Brasil. brunanadaletti@gmail.com \\ ${ }^{2}$ Universidade de Passo Fundo - UPF, Passo Fundo, Rio Grande do Sul, Brasil. carlagupf@gmail.com \\ ${ }^{3}$ Universidade de Passo Fundo - UPF, Passo Fundo, Rio Grande do Sul, Brasil. julio@upf.br
}

RESUMO: Trata-se de um estudo resultante de uma dissertação de mestrado, de abordagem qualitativa, que buscou avaliar a preparação dos sujeitos envolvidos no Programa de Educação pelo Trabalho (PET-Saúde) de uma universidade da região norte do RS para atuarem no SUS segundo os preceitos da integralidade e interprofissionalidade. É imprescindível o monitoramento e avaliação das orientações propostas pelas Diretrizes Curriculares Nacionais para os cursos da saúde, bem como pelos programas de reorientação da formação profissional, para tanto se faz necessária a construção e aplicação de instrumentos de avaliação e acompanhamento que funcionem como indicadores de rumos e de correções de percurso. Como resultados obtidos podemos enfatizar uma familiaridade dos sujeitos entrevistados com os conceitos utilizados pelos autores que trabalham o assunto; demonstraram em suas falas o quanto é claro em suas concepções o papel que o programa possui no processo de formação em saúde; também foi possível reconhecer que o programa está conseguindo incutir em seus participantes a necessidade e benefício do desenvolvimento de algumas habilidades essências para a qualificação do SUS; o reconhecimento dos participantes sobre a relevância da integração ensino-serviço-comunidade.

PALAVRAS-CHAVE: Formação em Saúde. Integralidade. Interprofissionalidade. SUS.

\begin{abstract}
This is a study resulting from a master's thesis, with a qualitative approach, that sought to evaluate the preparation of the subjects involved in the Education for Work Program (PET-Saúde) of a university in the northern region of RS to work in the SUS according to the precepts of integrality and interprofessionality. It is essential to monitor and evaluate the guidelines proposed by the National Curricular Guidelines for health courses, as well as the programs for reorienting vocational training, so that it is necessary to construct and apply assessment and follow-up tools that act as indicators of course and course corrections. As results we can emphasize a familiarity of the subjects interviewed with the concepts used by the authors who work the subject; demonstrated in their speeches how clear in their conceptions the role that the program has in the process of health training; it was also possible to recognize that the program is succeeding in instilling in its participants the need and benefit of developing some essential skills for qualifying the SUS; the recognition of the participants on the relevance of the teaching-servicecommunity integration.
\end{abstract}

KEYWORDS: Health education. Integrality. Interprofessionality. SUS. 


\section{Introdução}

A partir da Constituição Federal Brasileira de 1988 , a saúde passou a ser considerada um direito de todos e dever do Estado e o Sistema Único de Saúde (SUS) recebeu a incumbência de ordenar a formação de recursos humanos na área da saúde. Entre suas diretrizes, o SUS propõe a integralidade no cuidado em saúde, a qual é definida como um conjunto articulado e contínuo das ações e serviços preventivos e curativos, individuais e coletivos, exigidos para cada caso em todos os níveis de complexidade do sistema.

A integralidade deve ser pensada a partir das necessidades de saúde da comunidade. Desta forma, ao se identificarem tais necessidades, estas devem ser $\circ$ foco das intervenções das equipes assistenciais. As necessidades de saúde são complexas e devem ser claramente compreendidas pelos trabalhadores da saúde para que estes ofereçam uma atenção humanizada e qualificada. ${ }^{2}$

Para que a integralidade na assistência seja atingida, é indispensável que ocorram mudanças no processo de formação em saúde. Quando falamos em mudanças na formação, inevitavelmente é necessária a abordagem dos currículos, os quais impreterivelmente devem aproximar a teoria da prática, para que a capacitação dos acadêmicos ocorra na essência de atender às necessidades de saúde da população ${ }^{3}$.

Uma das principais estratégias para que a integralidade seja característica existente nos profissionais de saúde é a educação interprofissional (EIP), pois assim consegue-se ir ao encontro dos aspectos biopsicossociais e olhar $\circ$ processo saúde-doença em todas as suas dimensões, considerando a visão dos diversos profissionais envolvidos, deixando de lado a visão estritamente biomédica da saúde ${ }^{4}$.

EIP ocorre quando duas ou mais profissões aprendem com e sobre cada uma a fim de melhorar a colaboração e a qualidade do cuidado. ${ }^{5}$ Os estudantes de diferentes cursos aprendem sobre suas profissões, estabelecendo troca de aprendizagens, através da interação, aprendendo além dos conteúdos do seu próprio curso, também os dos outros e assim, entre si $^{6}$.
Devida a importância que possui, a EIP com foco na integralidade deve ser adotada tanto nos cursos de graduação como nos cursos de pós-graduação e educação permanente em saúde, para que assim os profissionais sejam constantemente lembrados e instigados, independente do seu nível de formação, a praticarem o cuidado centrado na integralidade ${ }^{7}$.

Em 2001 foram aprovadas as primeiras Diretrizes Curriculares Nacionais (DCN) para os cursos de graduação na área da saúde. Com o objetivo de proporcionar transformações na educação superior, elas defendem a substituição de um modelo centrado na individualidade, fragmentação do cuidado e rigidez dos currículos, por um modelo flexível, com foco na promoção e prevenção antes do tratamento e também metodologia e cenários de ensino diversificados. No entanto ainda nos dias atuais são encontradas diversas barreiras para que sejam implementadas, principalmente relacionadas à adesão dos docentes, pois muitos acreditam que a integração é sinônimo de ameaça para a qualidade de sua disciplina ${ }^{8}$.

O Ministério da Saúde (MS), através da Secretaria de Gestão do Trabalho e da Educação na Saúde SGTES, buscando reafirmar as mudanças propostas pelas $D C N$ e exaltar a integração ensino-serviço, bem como abordar integralmente o processo saúdedoença com ênfase na atenção básica, instituiu no ano de 2005 o Programa Nacional de Reorientação da Formação Profissional em Saúde (Pró-Saúde). O programa objetivou a aproximação das universidades com o SUS, defendendo essa prática como algo indispensável para $\circ$ aprendizado. Também propôs que as mudanças na formação ocorram a partir dos eixos orientação teórica, cenários de prática e orientação pedagógica. Tais eixos devem ser focados na integração das IES (Instituição de Ensino Superior) com o SUS, de tal forma que as demandas da população, os reparos às falhas na formação dos profissionais, a produção do conhecimento e principalmente o fortalecimento do SUS sejam alcançados?.

Passados três anos, em 2008 foi apresentado o PET-Saúde, no contexto do Pró-Saúde, o qual foi pensado para promover a formação de grupos de aprendizagem tutorial com atividades focadas no desenvolvimento do SUS e também para o forta- 
lecimento da Atenção Básica com uma aproximação mais íntima entre as IES, os serviços de saúde e a comunidade ${ }^{10}$. Até hoje já foram publicados seis editais do PET-Saúde.

A partir das colocações anteriores e da compreensão das mudanças que se fazem necessárias na formação da área da saúde, somos instigados a realizar algumas indagações frente ao tema, utilizando a seguinte problematização: Em que medida o programa governamental PET-Saúde está atingindo os seus objetivos e contribuindo para a melhoria do desempenho interprofissional no SUS em uma universidade comunitária?

objetivo deste estudo foi avaliar a preparação dos sujeitos envolvidos no PET-Saúde de uma universidade comunitária para atuarem no SUS, segundo os preceitos da integralidade e interprofissionalidade.

\section{Metodologia}

Esta pesquisa possui caráter qualitativo, a qual apresenta como preocupação central a minúcia da compreensão de um acontecimento, de um grupo populacional, de uma organização, entre outros. A abordagem qualitativa opõe-se a presunção que ampara um modelo único de pesquisa para todas as ciências ${ }^{11}$.

O protocolo de pesquisa foi aprovado sob o parecer $n^{\circ} 1.651 .027$, os sujeitos após informados, assinaram Termo de Consentimento Livre e Esclarecido

A coleta de dados foi realizada por meio de três etapas.

$1^{a}$ Etapa: Pré-Mapeamento - o intuito nessa etapa foi a realização de um levantamento a fim de identificar os ex-participantes do PET-Saúde da universidade. Como fonte foram utilizados os dados de identificação dos participantes fornecidos pela referida Universidade e também pelo site fns.saude.gov. br (Fundo Nacional de Saúde). Após o levantamento da identificação dos ex-participantes, foi elaborada uma planilha contendo as informações que nos possibilitaram a busca ativa desses indivíduos.
A seleção dos sujeitos a serem entrevistados ocorreu por amostragem intencional e orientada pelo critério de entrevistar pessoas de diferentes categorias profissionais e também de diferentes categorias no projeto (alunos, professores e profissionais), a fim de desvelar o fenômeno sob a integralidade como base da formação para o SUS.

$2^{a}$ Etapa: Mapeamento - nessa etapa de mapeamento dos ex-bolsistas, se utilizou como forma de contato a correspondência via e-mail ou mensagem telefônica. Foi um total de 9 (nove) ex-bolsistas entrevistados.

$3^{a}$ Etapa: Entrevistas - foram executadas as entrevistas semiestruturadas com questões norteadoras, as quais foram: 1. Como foi participar do PET-Saúde? 2. Que competências (conhecimentos, habilidades, atitudes e valores) você desenvolveu no PET-Saúde? 3. Houve alguma mudança na sua vida a partir do desenvolvimento das atividades do PET-Saúde? Se houve, quais foram?

Foi entrevistado 01 sujeito por curso, entre os cursos participantes dos diferentes editais do PETSaúde aprovados e desenvolvidos na instituição: Enfermagem (preceptor), Nutrição (tutor), Fisioterapia (aluno), Medicina (tutor), Odontologia (tutor), Serviço Social (coordenadora municipal do PET-Saúde), Medicina Veterinária (aluno), Farmácia (tutor) e Fonoaudiologia (aluno). As entrevistas foram gravadas no formato de áudio e integralmente transcritas. Conforme as orientações de Goldim (2000), os participantes foram identificados por códigos, mais especificamente por nome de flores, a fim de assegurar o sigilo de sua identidade.

O processo interpretativo, ou seja, o primeiro momento da análise das informações coletadas ocorreu de forma organizada e para que assim tivesse acontecido foram percorridas em quatro momentos. $O$ primeiro momento foi a preparação e reunião dos dados.

No segundo momento aconteceu uma análise dos dados de forma contextualizada com o intuito de reconstruir teoricamente a realidade.

Já no terceiro momento, o processo investigativo foi pautado no diálogo com os autores que trabalham 
com o tema em questão. Foi de extrema relevância - contato com os demais autores pois auxiliou no esclarecimento das dúvidas que surgiram durante a abordagem dos dados coletados.

E o quarto e último momento da interpretação dos dados foi caracterizado pela reinterpretação, ou seja, interpretamos as nossas primeiras interpretações. Para que conseguíssemos alcançar tal finalidade, realizamos uma síntese através da articulação entre os dados empíricos, os autores que trabalham sobre a temática e a análise feita sobre a conjuntura. Essa articulação e posterior reinterpretação permitiu a aproximação da pesquisa com a realidade mais ampla.

\section{Resultados e Discussão}

Dividimos os temas abordados nas entrevistas em três categorias de análise distintas. A categoria número 1 (um) aborda a integralidade e interprofissionalidade, a categoria número 2 (dois) engloba a educação permanente em saúde e a categoria número 3 (três) foi destinada à qualificação do SUS.

\section{Integralidade e Interprofissionalidade}

A análise desta categoria identificou alguns tópicos, que foram mais citados pelos entrevistados: aprendizagem interprofissional e a troca de experiências; comunicação interprofissional e da comunicação de rede; atuação integrada e prática colaborativa.

Explicitamos alguns fragmentos das entrevistas onde os conceitos foram abordados:

(...) Acredito também que tivemos a oportunidade de fazer uma aprendizagem interprofissional, envolvendo diferentes cursos, diferentes profissões, diferentes

formações de professores. Eu acho que trabalhar em equipe, respeitar as diferenças, exercício da ética profissional, a compreensão do que é comum na formação em saúde e o que é específico de cada profissional (Dendron, 2016).

(...) Então toda essa vivência do PET, essa troca de experiência com os profissionais enriquece enormemente a minha formação como profissional e como pessoa também, nesse trajeto todo tivemos oportunidade de conhecer diversas pessoas, muitos profissionais, de compreender contextos que às vezes julgávamos sem ter conhecimento de causa, e posso até dizer que na miscigenação entre pessoal e profissional, esse processo todo me encorajou (Amarilis, 2016).

Observamos fortes referências sobre a aprendizagem interprofissional e o compartilhamento de experiências. Assim, conforme os depoimentos, a interprofissionalidade trata-se de meio importante para o enriquecimento da formação profissional e consequente preparo qualificado para a atuação no SUS, vistas as trocas de conhecimentos e habilidades entre as diversas profissões da saúde que o PET-Saúde proporcionou.

Com a colocação anterior, é relevante retomar que um dos primordiais intuitos do PET-Saúde foi de modificar as práticas assistenciais e consequentemente refletir no modelo assistencial vigente, adotando como base das ações a integralidade do ser humano. Para que isso fosse alcançado adotou-se a perspectiva da EIP e do trabalho colaborativo, incutindo nos participantes do programa a importância que a interprofissionalidade possui e o quanto é indispensável'.

A EIP proporciona transformações consistentes no perfil dos profissionais, possibilita o desenvolvimento de conhecimentos, habilidades e atitudes para atuar com competência e ao mesmo tempo responder com coerência às necessidades sociais. Também pode coadjuvar na otimização da utilização dos recursos de saúde, considerando que as escolhas e ações praticadas serão discutidas interprofissionalmente ${ }^{12}$.

A aprendizagem e a troca de experiências interprofissionais descaracterizam a tendência da formação isolada e circunscrita a sua própria área de atuação. A EIP viabiliza a atuação integrada em equipe, na qual a colaboração e o reconhecimento da importância de cada uma das profissões predominam frente a competição profissional e a formação fragmentada". Também rompe com o "tribalismo das profissões", ou seja, a tendência de cada profissão atuar isoladamente, seja nos serviços de saúde ou no processo de formação ${ }^{13}$.

Teve uma influência bem direta em praticamente tudo, principalmente proatividade, o trabalho interdisciplinar,

conversar com outro pessoal. Pra ti ter noção eu tive que dar palestra pra pré-adolescente sobre drogas, 
uma coisa que eu nunca imaginei que eu ia ta fazendo na minha vida (Antúrio, 2016).

(...) E no PET eu tinha a oportunidade de conversar com o médico, com o enfermeiro, com o da farmácia que às vezes estava lá, e a gente pode vivenciar situações bem importantes (Gardenia, 2016).

Habilidade de comunicação, tanto entre profissional e usuário, como entre a equipe, entre todos os petianos, entre os próprios estabelecimentos que tinham no PET,

tinha UBS, tinha CAIS, tinha CAPS, então a gente conseguiu ter uma comunicação de rede (Tulipa, 2016).

Os depoimentos acima revelam uma atenção significativa destinada à importância da comunicação interprofissional e da comunicação de rede, salientando que isso proporciona a troca de informações e a vivência de situações importantes para a qualificação profissional.

Dessa forma enfatizamos que o compartilhamento do conhecimento visa cooperar com a formação de profissionais melhor preparados para a atuação em equipe, fazendo com que a qualidade da comunicação seja fundamental para a efetividade da atenção à saúde na perspectiva da integralidade. ${ }^{14}$

A comunicação é classificada como um dos principais desafios da interprofissionalidade e dos processos que por ela são envolvidos, pois os relacionamentos, sejam eles com outras equipes, outros setores ou mesmo entre a própria equipe no local de trabaIho, precisam de uma comunicação clara e objetiva para que tenham sucesso ${ }^{7}$.

A realidade atual traz a experiência de importantes mudanças sociais, como o perfil epidemiológico da população, aumento da expectativa de vida e a exigência de uma atenção à saúde que contemple a grande maioria das necessidades dos usuários. Para que se consiga enfrentar essas imposições de todos os níveis de complexidade dos serviços de saúde, a qualidade da comunicação interprofissional é indispensável ${ }^{14}$.

Indo ao encontro das colocações de alguns sujeitos entrevistados, a OMS defende que a EIP consegue desenvolver nos participantes habilidades de comunicação, de análise crítica e a valorização dos benefícios que 0 trabalho em equipe proporciona, bem como o crescimento profissional que é ocasionado pelo enfrentamento de desafios ${ }^{6}$.

Enfatizando a habilidade de comunicação, os profissionais que a possuem conseguem colaborar melhor com colegas de outras profissões, possuem uma facilidade em colocar em prática o conhecimento adquirido e também são dotados com o diferencial de interagir, negociar e trabalhar com profissionais de saúde de qualquer procedência ${ }^{6}$.

(...) Me proporcionou uma vivência bem peculiar perante a realização de um trabalho dentro de uma equipe multiprofissional e que foi de grande valia estar inserida na realidade da comunidade, porque isso gerou uma diversidade de ações que contribuíram com o aprendizado de todos, sejam profissionais, acadêmicos ou a própria comunidade, então todos os sujeitos envolvidos ampliaram seu aprendizado e seus conhecimentos (Gerbera, 2016).

(...) O PET possibilita que o trabalho se desenvolva não somente de uma maneira multiprofissional, não apenas pensando questões transdisciplinares, mas sim de uma forma interprofissional e com vistas às práticas colaborativas (Estrelícia, 2016).

Sobre a atuação de forma integrada, mencionada por um dos entrevistados, que também pode ser chamada de prática colaborativa, podemos mencioná-la como uma aliada da formação profissional com foco na integralidade, pois induz a identificação da interdependência das profissões e afasta a ideia de fragmentação da atenção à saúde ${ }^{7}$.

A interprofissionalidade, resulta na otimização do cuidado devido à integralização dos saberes, com as especificidades de cada profissão mantidas, para que assim se consiga suprir as complexas demandas do cenário de saúde atual ${ }^{15}$.

\section{Educação Permanente em Saúde}

Na segunda categoria abordamos os relatos dos participantes entrevistados sobre a Educação Permanente em Saúde. Também surgiram tópicos mais enfatizados: interlocução entre ensino e serviço; atividades de extensão; conhecimento sobre o SUS. 
(...) Foi e tem sido uma experiência muito válida, muito positiva, agregadora, e que permite de fato a interlocução, entre o que a gente ensina e aprende na universidade, na academia, com a realidade do mundo do trabalho, dos serviços de saúde, especialmente da atenção básica, que é o local de formação que os meus grupos tutoriais participaram. Muito importante

destacar, que acaba ocorrendo o exercício da integração entre o ensino, a pesquisa e a extensão, mas que infelizmente acaba sendo restrito ao número

de alunos contemplados pelo PET, enquanto que na realidade, na minha opinião, esse processo é o que tem

que acontecer em todos os cursos de graduação da área da saúde e de outras áreas a fim

(Amarilis, 2016).

Em toda parte que tu vais e começa a entender esse processo todo de fazer uma formação mais globalizada, fica tudo muito na teoria, mas na prática mesmo a gente tem dificuldade de fazer. A fala prática contamina o aluno, e lamentavelmente o que eu acho que é pouco, é que a gente não consegue inserir mais alunos, você contamina poucas pessoas. Essa engrenagem toda do ensino-serviço tem que ser mais incrementada, que a gente não fique só teorizando e que os alunos consigam realmente fazer essa vivência lá no serviço (Gardenia, 2016).

Inicialmente um grande desafio porque de primeiro momento eu nunca tinha tido uma aproximação com a área de ensino, a interface de saúde e ensino, pensar questões de educação relacionadas à saúde, então

foi um desafio bastante grande, essa interface do

SUS escola com a universidade, pensando ensinoserviço-comunidade, isso tem sido algo maravilhoso profissionalmente pra mim, não somente no âmbito

profissional mas também a nível pessoal de um

amadurecimento bastante intenso, principalmente porque ali a gente tem se deparado com a verdadeira realidade da prática em saúde e também da formação em saúde, ou seja, tudo aquilo que se pensa, se estuda, se pesquisa, muitas vezes só no âmbito teórico, o PET possibilita por meio de um contato bastante próximo com a comunidade que a gente possa perceber a riqueza desse processo e ao mesmo tempo o quanto ainda é necessário avançar (Estrelícia, 2016).

Podemos considerar que a importância da interlocução entre teoria e prática ou ensino e serviço é algo muito claro para os participantes, vistas as vezes que o tema foi mencionado nos relatos. Enfatizam que através das atividades que o programa proporciona consegue-se visualizar com maior proximidade a integração entre ensino-serviço-comunidade. Destacam também que a prática contamina o aluno, colocando-o mais próximo da realidade da comunidade.

A compreensão por parte dos participantes do estudo sobre a relevância que a tríade ensino-serviço-comunidade possui no processo de formação, vai ao encontro do conceito do programa PET-Saúde que tem como horizonte a iniciação ao trabalho e vivências de acordo com as necessidades do SUS. Busca adentrar os sujeitos envolvidos no campo de prática, com a intenção de identificar as reais demandas dos serviços de saúde e assim utilizá-las como fonte de conhecimento e possíveis temas para o desenvolvimento de pesquisas científicas ${ }^{16}$.

A integração ensino-serviço é o desenvolvimento das atividades entre os discentes e docentes juntamente com os trabalhadores dos serviços de saúde, visando a melhoria da qualidade da atenção à saúde, bem como a qualificação dos profissionais envolvidos. Essa aproximação entre a formação profissional e a assistência à saúde possibilita a articulação entre - saber e o fazer, no entanto para que aconteça de forma efetiva é necessário que haja concordância e compartilhamento dos mesmos objetivos e ideais entre as universidades, as instituições de saúde e a comunidade ${ }^{17}$.

Quando eu fui estudar sobre o SUS dentro do meu curso, eu já tinha toda uma bagagem porque o PET me proporcionou isso, foi onde eu vivi minhas primeiras experiências, fiz meus primeiros atendimentos,

foi aonde eu tive noção do que era fazer uma pesquisa, foi aonde eu tive a primeira noção do que era fazer uma intervenção, fazer um projeto, do que é fazer um artigo (Tulipa, 2016).

(...) e o PET deu oportunidade de dar uma arejada aí no processo de trabalho, fazendo com que a gente revisse alguns fluxos e principalmente se organizar para fazer bem, tanto a assistência como o ensino, e de ter dado uma incrementada também na nossa capacidade de fazer atividade de extensão dentro da unidade de saúde (Dendron, 2016).

A primeira coisa que me vem à mente é sair da zona de conforto. A gente sempre é muito acomodado na nossa graduação, então sair da aula, da sala de aula e ir a campo foi uma coisa muito forte, pelo menos pra mim, pra poder fazer todas as atividades que foram 
propostas. Foi uma coisa que te tira do teu lugar e tenta te colocar em outro. É um desafio, eu digo que foi um desafio pra mim (Antúrio, 2016).

Também encontramos nos relatos muitas menções sobre a relevância que as atividades de extensão e pesquisa possuem. Foi realçado que o programa permite aos participantes terem o conhecimento do que são, de fato, as atividades de extensão e as implicações positivas que trazem para o processo de formação e/ou desenvolvimento profissional.

A experiência na comunidade é um espaço para deslocar para a prática o conhecimento proporcionado pela teoria, permitindo assim uma vasta ampliação da compreensão do processo saúde-doença. As atividades de extensão proporcionam sensação de utilidade e maior aprendizagem pessoal e profissional aos envolvidos.

É indispensável a atuação na comunidade pois esta, além de caracterizar de forma positiva $\circ$ processo de formação, também permite a indissociabilidade do ensino-pesquisa-extensão ${ }^{18}$.

As atividades de extensão oportunizam aos participantes diferentes experiências de ensino-aprendizagem e tais vivências, pelo conteúdo que possuem, propiciam a formação de um profissional com características diferenciadas, entre elas $\circ$ senso crítico, a habilidade reflexiva, a proatividade e a capacidade de atuar em equipe e mais ainda, em equipe multiprofissional ${ }^{19}$.

As atividades desenvolvidas no âmbito da Atenção Básica levam ao desenvolvimento de diversas potencialidades e o PET-Saúde, enquanto programa governamental, possui como uma de suas prioridades propiciar a execução de práticas nos espaços de saúde e da comunidade baseadas nos princípios do SUS e focadas para o atendimento qualificado ao usuário ${ }^{16}$.

Os projetos de extensão e pesquisa podem ser vistos como motivadores dos docentes, discentes e profissionais da saúde envolvidos, pois. Por meio do desenvolvimento das atividades é possível contextualizar a realidade social e cultural da comunidade que estão inseridos e também porque através da investigação se consegue refletir sobre suas próprias práticas ${ }^{3}$.
Cabe salientar ainda que o PET-Saúde é um projeto voltado para a capacitação e desenvolvimento profissional através da reorientação da formação de todos os cursos da área da saúde e desenvolve nos participantes habilidades primordiais para que a atenção à saúde dispensada seja a mais qualificada possível. Relacionado ao desenvolvimento de pesquisas, compete ao programa sustentar e orientar o desenvolvimento de pesquisas que permitam - crescimento profissional, desenvolvimento técnico-científico, desenvolvimento institucional, dentre outros. O perfil desse programa é uma referência que se mostra eficaz na concepção do ensino-pesquisa e extensão das IES ${ }^{20}$.

Sempre indico para quem tem interesse que procure o programa, porque a graduação não nos dá o que o preparo que em dois anos de PET eu tive, não tenho dúvida que nenhuma faculdade prepara tão bem - profissional pro serviço de saúde pública como - PET-Saúde (Dália, 2016).

Mudei minhas atitudes e meus valores perante ao SUS também, acompanhando principalmente as enfermeiras que eu acompanhei, vi que o trabalho delas é bem árduo para conseguir atender as populações

(Narciso, 2016).

Outro ponto abordado foi o conhecimento sobre o SUS que o programa proporciona referente a sua história, desenvolvimento e funcionamento e sua base legal. Coloca os participantes em uma relação mais íntima com a legislação relacionada à saúde pública, documentos, cartilhas, normas técnicas, entre outros, causando a propagação de um conhecimento mais detalhado sobre o sistema de saúde.

Devemos considerar que os participantes do PETSaúde irão atuar, direta ou indiretamente, com o ser humano, o qual pode ser visto como complexo e singular. É vital que sejam entendidos sobre a realidade da qual irão atuar, se apropriando dos conhecimentos especíicicos relacionados ao SUS, como as políticas públicas de saúde e desenvolvimento ${ }^{21}$.

Tanto ○ MS quanto $\circ$ MEC compartilham da preocupação em manter uma relação de cooperação entre o sistema de saúde e as IES. É proposta constante a conexão ensino-aprendizagem sobre o SUS, principalmente sobre conhecer e apropriar-se do sistema de saúde como um todo, em todas as suas 
particularidades e especificidades, para que assim as decisões sejam tomadas e as ações sejam planejadas de forma condizente aos princípios do SUS ${ }^{22}$.

\section{Qualificação do SUS}

Na terceira e última categoria de análise abordamos as colocações feitas pelos entrevistados a respeito da qualificação do SUS que ocorre consequentemente à execução do PET-Saúde. Em suma, disseram que, reunindo todas as habilidades que são desenvolvidas nos sujeitos envolvidos no programa, acrescidas do enriquecimento intelectual, bem como da capacidade de relacionamento interpessoal e interprofissional, temos como resultado um profissional muito mais qualificado e preparado para trabalhar e atender às necessidades do SUS. A seguir eis alguns dos relatos:

(...) Na academia muitas vezes a gente se debruça sobre os documentos, dispositivos legais, as portarias e as leis. O papel aceita tudo e a teoria é escrita por

grandes pensadores com o objetivo de ser o mais perfeito possível, mas quando a gente se depara com a realidade, com a unidade básica de saúde, com as necessidades da comunidade, não é bem assim, então acho que uma competência importante é essa tolerância entre os diferentes interesses sejam dos usuários, dos pacientes, das equipes de saúde, dos professores, dos alunos, então uma habilidade que a gente foi desenvolvendo ao longo desse tempo foi fazer essa convergência dos interesses, sempre pensando no objetivo maior do PET que é qualificar a atenção básica (Amarilis, 2016).

(...) Outra coisa também, a gente troca ideia com as outras pessoas, que faz com que a gente saia do nosso mundinho e consiga enxergar ao nosso redor, o que

é muito difícil a pessoa fazer hoje em dia, a gente tá tão concentrado na nossa vida ali que muitas vezes esquece do outro, que tu olha pro lado e tem uma pessoa precisando da tua ajuda e muitas vezes tu não enxerga. Se eu não tivesse participado do PET com certeza minha vida seria diferente e eu não perceberia as coisas que eu percebo hoje (Antúrio, 2016).

Foi citado o conhecimento da realidade da comunidade na qual se está inserido como ponto muito importante para o desenvolvimento de estratégias e ações que atendam à demanda local. Mergulhar no contexto da comunidade é imprescindível para uma atenção à saúde qualificada e resolutiva.
O profissional deve estar envolvido com a comunidade e possuir conhecimento sobre sua realidade e necessidades é muito importante para que sejam definidas, implementadas e avaliadas as ações, tanto coletivas quanto individuais, sejam elas de prevenção ou assistência. Conhecer o contexto da comunidade permite adotar ações que de fato venham a colaborar e solucionar na medida do possível os problemas encontrados ${ }^{23}$.

A realidade da comunidade local deve ser problematizada e refletida, pois só assim é reconhecida com propriedade. Para que a reflexão ocorra de forma efetiva deve-se estabelecer uma conexão entre os fenômenos/acontecimentos e seu contexto. Compreender a realidade local faz com que a subjetividade dos fatos também seja compreendida ${ }^{24}$.

No processo de formação em saúde, as IES possuem um papel ímpar na contribuição para as melhorias das condições de saúde, uma vez que são responsáveis pela formação dos futuros profissionais. Estarem atentas e preocupadas com as necessidades de saúde da população é indispensável para que desenvolvam atividades de ensino, pesquisa e extensão, inserindo dessa forma os alunos ainda em formação na realidade das comunidades ${ }^{25}$.

(...) Uma das coisas que aprendi foi isso, conseguir enfrentar desafios ou a conseguir fazer coisas pela primeira vez. Quando tu entra naquele cenório e nunca viu aquilo e aprende a se adaptar, a ter atitude. $E$ o conhecimento, o conhecimento sobre a saúde, sobre - profissional da saúde. A escrita foi uma habilidade que eu consegui desenvolver dentro do PET por causa da escrita de projetos, de artigos, enfim. Habilidade de escuta, por escutar o usuário, escutar o grupo de trabalhadores que eu fiz minha intervenção. Habilidade de intervenção, habilidade de planejamento de atividades, de mediação de grupos (Tulipa, 2016).

Proporcionou também o desenvolvimento de postura ética e pró-ativa perante todas as situações encontradas, também foi proporcionada a utilização de criatividade nas diversas formas de comunicação entre os sujeitos, bem como também a dedicação de cada um nas ações desenvolvidas, então foi bastante importante a gente ter que ajudar e buscar a solução para amenizar diversos problemas perante as situações da comunidade (Gerbera, 2016). 
(...) Nos ensina sim o desenvolvimento de atitudes

e responsabilidades, de ética, valores então, de compromisso com as pessoas, de saber que o direito à saúde precisa ser exercido. Eu tenho certeza que todos os participantes do PET saem fortalecidos, com uma visão de homem e de mundo mais humanizada, porque as realidades de sofrimento que a gente se

depara nos territórios de atenção à saúde muitas vezes nos desumanizam, e o PET é por excelência um lócus de construção coletiva desse conhecimento e essa força permite que todos os participantes passem por este processo e saiam deste processo levando muito conhecimento, habilidade profissional, relacional, e o essencial que é poder olhar para as pessoas e ter a magnitude de que cabe a nós o cuidado destas, um respeito máximo à sua condição de pessoa

(Estrelícia, 2016).

O que eu desenvolvi com o programa foi isso, a questão da ética, de ser mais coerente com o que eu posso e devo fazer, com certeza hoje eu sei como funciona a rede e tenho mais calma, mais paciência, que as coisas não se resolvem como a gente acha que tem que ser, sei como me comunicar com o paciente talvez de uma forma melhor que o outro profissional (Dália, 2016).

Conseguimos caracterizar através das declarações dos entrevistados, um reconhecimento sobre o papel que o PET-Saúde possui no desenvolvimento de habilidades profissionais essenciais, tais como ética, proatividade, atenção humanizada, empatia, entre outros.

Práticas de atenção pautadas na humanização e no estabelecimento de vínculos entre os profissionais e usuários possuem chances significativamente maiores de atenderem o sujeito na sua integralidade. Cabe, por sua vez, ressaltar que a criação do vínculo deve ser pensada em todos os momentos de contato com o usuário, entre eles o acolhimento, que é o recebimento da comunidade no serviço de saúde, o qual deve ser planejado considerando o significado da palavra, que é: "ato ou efeito de acolher, de oferecer refúgio, abrigo, agasalho"14.

Relacionado à habilidade da ética profissional, devemos refletir sobre a abrangência e importância da atenção básica no campo da saúde, exaltando assim a demanda por profissionais dotados com a capacidade de uma atuação proativa, a qual deve ser amparada pela interprofissionalidade e pelo real conhecimento do processo saúde-doença, inclusive de seus múltiplos condicionantes. Essa necessidade requer consideráveis mudanças no processo de formação, bem como a execução de projetos e programas que venham a consolidar essas modificações no modelo assistencial ${ }^{25}$.

Indo ao encontro das colocações relacionadas a habilidade de ser proativo, podemos citar os princípios e objetivos do programa PET-Saúde, bem como o perfil das atividades práticas que os envolvidos no programa são expostos, salientando como uma das habilidades importantes, a qual é desenvolvida e aprimorada, a proatividade profissional. Tal termo possui o seguinte significado: "é o comportamento de antecipação e de responsabilização pelas próprias escolhas e ações frente às situações impostas pelo meio"16.

\section{Considerações finais}

Chega o momento de tecermos nossas considerações finais, fruto de um trabalho que teve como ponto de partida a integralidade no contexto da formação em saúde. A fim de compreender o complexo cenário da formação do profissional da saúde, percorremos um caminho com o aprofundamento de temáticas importantes que influenciaram na história e evolução do processo de formação em saúde.

Para que fossem esclarecidos os primeiros passos que foram dados rumo às modificações da formação condizentes com as necessidades da população, recorremos aos principais documentos que embasaram a reorientação da formação profissional em saúde, como a Lei de Diretrizes e Bases e as DCN dos cursos de graduação da área da saúde. Esses documentos permitiram uma compreensão mais clara e objetiva acerca das características da mudança curricular. Também nos permitimos o contato com autores que refletem sobre a problematização da educação nos cursos da saúde, conseguindo dessa forma estabelecer um diálogo entre saúde e educação. Cabe enfatizar que, quando abordamos o vínculo entre saúde e educação, muitos são os cenários e sujeitos envolvidos. Quando nos referimos aos sujeitos, mais enfaticamente, estamos falando dos usuários, gestores, professores, alunos e profissionais da saúde. 
Após realizarmos as entrevistas com os participantes do estudo, foi possível identificar uma grande familiaridade com os termos e conceitos mais frequentemente utilizados pelos autores que escrevem sobre o tema. Isso reflete positivamente no contexto do quanto, de fato, os participantes dominam a globalidade do programa com o qual estavam envolvidos. Também cabe salientar o fato de serem ex-participantes e assim podemos observar a fixação dessa compreensão em suas bagagens culturais, - que qualifica seus desempenhos, pois tudo que temos um entendimento com maior profundidade conseguimos utilizar com maior eficiência e sucesso.

Refletindo sobre a lógica do Programa PET-Saúde e sua finalidade de criação, a qual foi incutir o processo de educação permanente em saúde no dia-a-dia das práticas de atenção, possuindo como princípios embasadores de sua operacionalização a integralidade e interprofissionalidade, podemos destacar que os ex-participantes do PET-Saúde da universidade demonstraram em suas falas o quanto é claro em suas concepções o papel marcante que - programa possui no desenvolvimento dessas duas habilidades, pois enfatizaram com veemência o enriquecimento que isso trouxe aos seus processos de formação e desenvolvimento profissional.

Quando comparamos os objetivos idealizados pelo PET-Saúde às falas dos entrevistados e aos seus respectivos conteúdos, podemos observar que, na medida do possível, está se conseguindo instigar aos participantes do programa a importância do desenvolvimento dessas habilidades e do alcance mais próximo possível dos objetivos propostos, principalmente no que diz respeito à formação dos profissionais de saúde com perfil adequado às demandas populacionais locais, à sensibilização e humanização dos profissionais e à articulação entre ensino e serviço na área da saúde.

A partir do reconhecimento dos entrevistados sobre a importância da imersão do profissional na realidade da comunidade na qual está inserido, bem como da relevância da formação generalista com foco na integralidade do sujeito, podemos apontar um caminho aberto para a efetivação das mudanças propostas pelas DCN dos Cursos de Graduação da Saúde, mesmo que ainda existam obstáculos a serem ultrapassados para que a total aplicação seja atingida.
O reconhecimento dos indivíduos participantes do estudo sobre a importância da integração ensino-serviço deve ser valorizado, pois reflete no desenvolvimento da participação ativa e da formação do pensamento crítico. A união ensino-serviço é indissociável entre teoria e prática. E a prática, mais enfaticamente, é o momento em que o pensar e o agir caminham juntos.

A Interprofissionalidade foi abordada pelos participantes da pesquisa como uma oportunidade para vivenciar as experiências das demais profissões da saúde e ainda potencializar o respeito perante as diferenças e opiniões do outro. Desta forma, a interprofissionalidade permite 0 desenvolvimento de um perfil de profissional necessário ao mercado de trabalho atual.

No cenário da reorientação da formação profissional em saúde, podemos nos colocar na condição de construtores de pontes, pontes estas que se encontram no meio do caminho entre 0 passado criticado e o futuro desejado. Ainda em um momento de transformações, o que nos motiva a seguir rumo à efetivação de um sistema de saúde que cumpra seus princípios. Além disso, também precisamos salientar a necessidade constante de ampliar a investigação nesta área, principalmente relacionado às mudanças curriculares nas quais as estratégias estejam presentes.

\section{Contribuições dos autores}

Araújo BN participou da concepção, delineamento, busca e análise qualitativa dos dados da pesquisa, interpretação dos resultados, redação do artigo científico. Gonçalves $C B C$ participou da concepção, do delineamento e redação do artigo científico. Bertolin JCG participou da concepção e delineamento do artigo científico.

\section{Conflitos de interesses}

Nenhum conflito financeiro, legal ou político envolvendo terceiros (governo, empresas e fundações privadas, etc.) foi declarado para nenhum aspecto do trabalho submetido (incluindo mas não limitandose a subvenções e financiamentos, conselho consultivo, desenho de estudo, preparação de manuscrito, análise estatística, etc). 


\section{Referências}

1. Brasil. Constituição, 1988. Constituição da República Federativa do Brasil. Brasília: Senado; 1988.

2. Stotz EN. Necessidades de saúde: mediações de um conceito: contribuições das Ciências Sociais para fundamentação teórico-metodológica de conceitos operacionais da área de planejamento em saúde [Tese]. Rio de Janeiro: Escola Nacional de Saúde Pública, Fundação Oswaldo Cruz; 1991.

3. Ceccim RB, Feverwerker LCM. O Quadrilátero da Formação para a Área da Saúde: ensino, Gestão, Atenção e Controle Social. PHYSIS: Rev Saúde Coletiva. 2004;14(1):41 65. doi: 10.1590/S0103-73312004000100004

4. Batista NA. Educação interprofissional em saúde: concepções e práticas. Caderno FNEPAS. 201 2;2:25-28.

5. Centre for Advancement of Interprofessional Education. Interprofessional education guidelines [Internet]. 2017 [acesso em 2017 out 25]. Disponível em: https://www.caipe.org/ about-us

6. Organização Mundial de Saúde. Departamento de Recursos Humanos. Marco de Ação em Educação Interprofissional e Prática Colaborativa. Genebra: 2010.

7. Barr H, Koppel I, Reeves S, Hammick M, Freeth D. Effective interprofessional education: arguments, assumption \& evidence. Oxford: Blackwell; 2005.

8. Stella RCR, Puccini RF. A formação profissional no contexto das Diretrizes Curriculares Nacionais para o curso de medicina. In: Puccini RF, Sampaio LO, Batista NA. A formação médica na Unifesp: excelência e compromisso social. São Paulo: Editora Unifesp, 2008. P. 53-69

9. Brasil. Programa Nacional de Reorientação da Formação Profissional em Saúde. Pró-Saúde: objetivos, implementação e desenvolvimento potencial. Brasília, DF: Ministério da Saúde. Ministério da Educação; 2007.

10. Brasil. Ministério da Saúde. Portaria $\mathrm{n}^{\circ} 1$, de 5 de fevereiro de 2010. Homologa o resultado do processo de seleção dos Projetos que se candidataram ao Programa de Educação pelo Trabalho para a Saúde - PET-Saúde 2010/2011. Brasília, Diário Oficial [da] República Federativa do Brasil. $2010 a$.

11. Goldenberg M. A arte de pesquisar: como fazer uma pesquisa qualitativa em ciências sociais. Rio de Janeiro: Record; 1997.

12. Goelen G, De Clercq G, Huyghens L, Kerckhofs E. Measuring the effect of interprofessional problem-based learning on the attitudes of undergraduate health care students. Med Educ. 2006;40(6):555-561. doi: $10.1111 / i .1365-2929.2006 .02478 . x$
13. Frenk J, Chen L, Bhutta ZA, Cohen J, Crisp N, Evans T, Fineberg $\mathrm{H}$ et al. Health professionals for a new century: transforming education to strengthen health systems in an interdependent world. The Lancet. 2010;376(9756): 192358. doi: $10.1016 /$ S0140-6736(10)61854-5

14. Peduzzi M, Norman IJ, Germani ACCG, Silva JAM, Souza GC. Educação interprofissional: formação de profissionais de saúde para o trabalho em equipe com foco nos usuários. Rev esc enferm USP. 2013;47(4): 977-983, 2013. doi: $10.1590 /$ S0080-623420130000400029

15. Interprofessional Education Collaborative Expert Panel. Core competencies for interprofessional collaborative practice: report of an expert panel. Washington, D.C.: Interprofessional Education Collaborative; 2011.

16. Brasil. Ministério da Saúde. Ministério da Educação. Portaria Interministerial $n^{\circ} 1802$. Institui o Programa de Educação pelo Trabalho para a Saúde - PET-Saúde. Brasília, Diário Oficial [da] República Federativa do Brasil. 2008.

17. Feverwerker LCM. Gestão dos processos de mudanças na graduação em medicina. In: Marins JJN, Rego S, Lampert JB, Araújo JGC. Educação Médica em transformação: instrumentos para a construção de novas realidades. São Paulo: Hucitec; 2004.

18. González AD, Almeida MJ. Movimentos de mudança na formação em saúde: da medicina comunitária às diretrizes curriculares. PHYSIS: Rev de Saúde Coletiva. 2010;20(2):551-570. doi: 10.1590/S010373312010000200012

19. Carvalho JAM, Garcia RA. O envelhecimento da população brasileira: um enfoque demográfico. Cad Saúde Pública. 2003;19(3):725-733. doi: 10.1590/S0102$311 \times 2003000300005$

20. Brasil. Ministério da Saúde. Ministério da Educação. Portaria interministerial $n^{\circ} 422$, de 3 de março de 2010. Estabelece orientações e diretrizes técnico-administrativas para a execução do Programa de Educação pelo Trabalho para a Saúde - PET Saúde, instituído no âmbito do Ministério da Saúde e do Ministério da Educação. Brasília, Diário Oficial [da] República Federativa do Brasil. $2010 b$.

21. Dias HS, Lima LD, Teixeira M. A trajetória da política nacional de reorientação da formação profissional em saúde no SUS. Ciênc saúde coletiva. 2013;18(6):1613-24. doi: $10.1590 /$ S1413-81232013000600013

22. Brasil. Ministério da Saúde. Secretaria de Gestão do Trabalho e da Educação na Saúde. AprenderSUS: o SUS e os cursos de graduação na área da saúde. Brasília: Departamento de Gestão da Educação na Saúde; 2004. 
23. Cecílio LCO. As necessidades de saúde como conceito estruturante na luta pela integralidade e equidade na atenção em saúde. In: Pinheiro R, Mattos R A (Org.).

Os sentidos da integralidade na atenção e no cuidado à saúde. Rio de Janeiro: UERJ, IMS: ABRASCO, 2001.

24. Campos FE, Pierantoni CR, Viana ALA, Faria RMB, Haddad AE. Os desafios atuais para a educação permanente no SUS. Cadernos RH saúde. 2006;3(1):41-51.

25. Gonze GG, Silva GA. A integralidade na formação dos profissionais de saúde: tecendo valores. PHYSIS: Rev de Saúde Coletiva. 2011 ;21 (1): 129-146. doi: 10.1590/ $\underline{\text { s0103-73312011000100008 }}$ 